\title{
ANALYSIS OF THE CHANGES MADE IN THE OFFICIAL GAME RULES OF VOLLEYBALL THROUGH THE DOCUMENT ANALYSIS METHOD
}

\author{
Uluöz Eren ${ }^{1 *}$ \\ ${ }^{1}$ Çukurova University, Sarıçam/Balcalı, Adana 01380, Turkey
}

Keywords: volleyball, official game rules, rule changes.

\begin{abstract}
The purpose of this study is to set forth the changes made in the purposes of rule changes. The document analysis method, one of the qualitative analysis methods based on the collection of data by examining the existing records and documents, has been used in this study. It has been noted upon examining the findings attained as a result of the analysis that the major rule changes made could be mainly grouped under six headings. These may be listed as, "improvement of the playing court and physical conditions", "protection of player health”, “increasing game continuity by reducing interruptions”, "enhancing spectator pleasure by increasing rally durations”, "increasing TV broadcasts" and "standardization between volleyball and beach volleyball”. In spite of the positive developments, there are players, trainers, spectators and sports commentators who believe that certain changes such as "partial freedom in the net contact and crossing over to opponent's court” however, might increase player injuries although they increase game continuity.
\end{abstract}

\section{Introduction}

Volleyball is a sports branch in which millions of individuals participate with recreational, amateur and professional purposes. Major development and modification processes have been experienced in the volleyball sport ever since it has emerged in the continent of America in 1890's. In the volleyball sport which has drawn the interest of an increasing number of people in a short period of time, a need has been felt for more clear rules and setting up tournaments in order to organize and meet the high participation demand as we have lived through the 1930's. In the year 1947, Fédération Internationale de Volleyball” (FIVB) has been established in Paris by the joining and operating of many countries all over the world (FIVB, 2014). National federations and continental federations had begun to be established in the participating countries as well, as of this date. FIVB has continued its operations as the main establishment within this organization of the volleyball sport throughout the world ever since the date

\footnotetext{
*E-mail: proferde@hotmail.com
} 
it had been founded. The volleyball sport has become one of the most widespread sports branches, in terms of both the number of those who play it and the number of those who watch it played, through the efforts of the national federations, continental federations and FIVB (FIVB, 2011). It has been reported that, the volleyball sport, which has undergone considerable changes and developments since the day it has emerged, is played at least once a week by nearly 800 million people all over the world. According to the FIVB data however, while the number of licensed players is nearly 33 million throughout the world in general, the total number of persons interested in this sport with recreational purposes is approaching 200 million, together with the number of those who play volleyball (FIVB, 2014; volleyball.com, 2015). The fact that the volleyball has become such a widespread sport is due to its undergone a continuous process of development. This continuous development in the volleyball sport has been accompanied by tens of changes and modifications in the structure and rules of the game as well, during a period of more than one hundred years. As it is done in many of the other branches of sports, modifications and changes are also made in the volleyball sport from time to time. FIVB is recognized as the sole authorized entity with regard to rule changes (FIVB, 2016 ${ }^{\mathrm{a}}$ ). Nevertheless, national federations publish clarifying and regulative communications pertaining to special situations not adequately explicated in the official rule books.

Although FIVB is the only rule maker worldwide, it does not prefer to exercise this authority as a single entity with regard to rule changes. There are five different continental federations that operate in coordination with FIVB. These may be listed as the Asian Volleyball Federation (AVC), Confederation Africana de Volleyball (CAVB), Confederation European de Volleyball (CEV), Confederation Sudamericana de Voleibol (CVS) and the North, Central America and Caribbean Volleyball (NORCECA). There are 220 national federations operating under these continental federations (FIVB, 2011). Views pertaining to rule changes and modifications voiced by the actors of the game such as the players, trainers, referees and media are discussed within the bodies of the national federations, continental federations and FIVB, respectively. The rule changes that are considered as really needed as a result of these discussions are taken up in detail in the referee training courses, development seminars and workshops on special topics held by FIVB. Ideas concerning the rule changes to be made are further developed in detail in these meetings and are finally concluded and published by FIVB in the world-wide congresses held at specific intervals. Numerical values received from various scientific research protects and FIVB, continental federations and national federations have been assessed throughout all the stages of this decision making process (FIVB, 2014; FIVB, 2012; FIVB, 2010; FIVB, 2008; FIVB, 2016 ${ }^{\text {b). }}$

Radical changes and modifications have been implemented in volleyball especially during the last 30 years. Changes and modifications made in the 
official game rules however, affect the structure of the volleyball sport and its participants directly.

\section{Material and methods}

In this study, it has been analyzed that the basic changes carried out in the official game rules and to determine with what purpose these changes have been made and which areas they have concentrated on.

Method and data collection

The "Official Volleyball Rules Books" periodically published by FIVB has been used as the main source in the research. The document analysis method, which is one of the qualitative analysis methods, and is especially based on the collection of data by analyzing the existing records and documents, has been employed in the study. The "Official Volleyball Rules Books" periodically published by FIVB has been used as the main source in the research. In order to avoid the negative effects of inadvertent and exaggerated subjectivity, unintentional possibilities of erring that might lead to problems in the results of the research, the data collection and data analysis processes of the study, have been carried out separately by three different researchers who are component in the areas of volleyball sport and rule changes. Two different researchers have analyzed all the documents related to rule changes separately, independent of one another, as shown in the following model (Fig. 1), and have formed their own findings. A third researcher however, has undertaken the duty of checking the relevant findings obtained and the intermediate analyses performed.

The researchers have prepared the changes in the rules so as to categorize those by performing codings related to rule changes made during the analysis process. Following the completion of the coding process, the researchers have formed themes related to the rule changes in the light of the output they had obtained, again, independently of one another. Then, the two researchers have shared their coding and thematizing processes with other researchers and have attempted to form different points of view. In the conclusion stage, all the researchers have come together and given the final form to the all codings and thematizations.

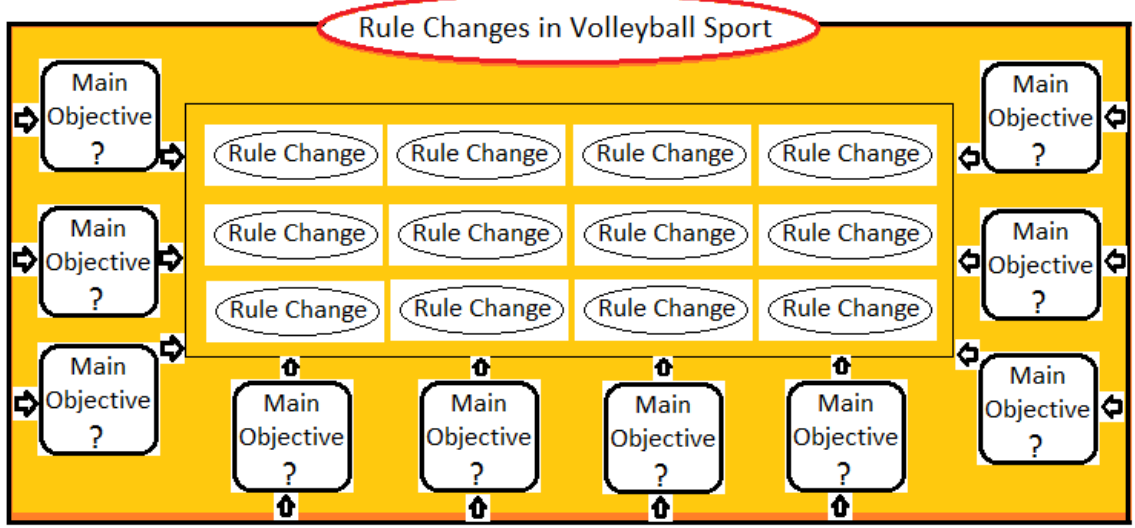

Figure 1. Initial Model Related to the Analysis of the main Objectives in Rule Changes 
The models formed separately by the researchers have then been compiled by the three researchers and the conclusive model has been formed. After the conclusive model was formed, the findings obtained in the research have been analyzed on the basis of the subject topics from related issues of the rule books. The aims of the rule changes made have been identified and it has been attempted to define areas on which the changes made concentrated on.

\section{Results and discussions}

It has been noted upon examining the changes and modifications made in the official volleyball rules that the rule changes made essentially aimed at making improvements on certain main aspects. The following model has been attained in the light of the findings as a result of the document analyses within the study.

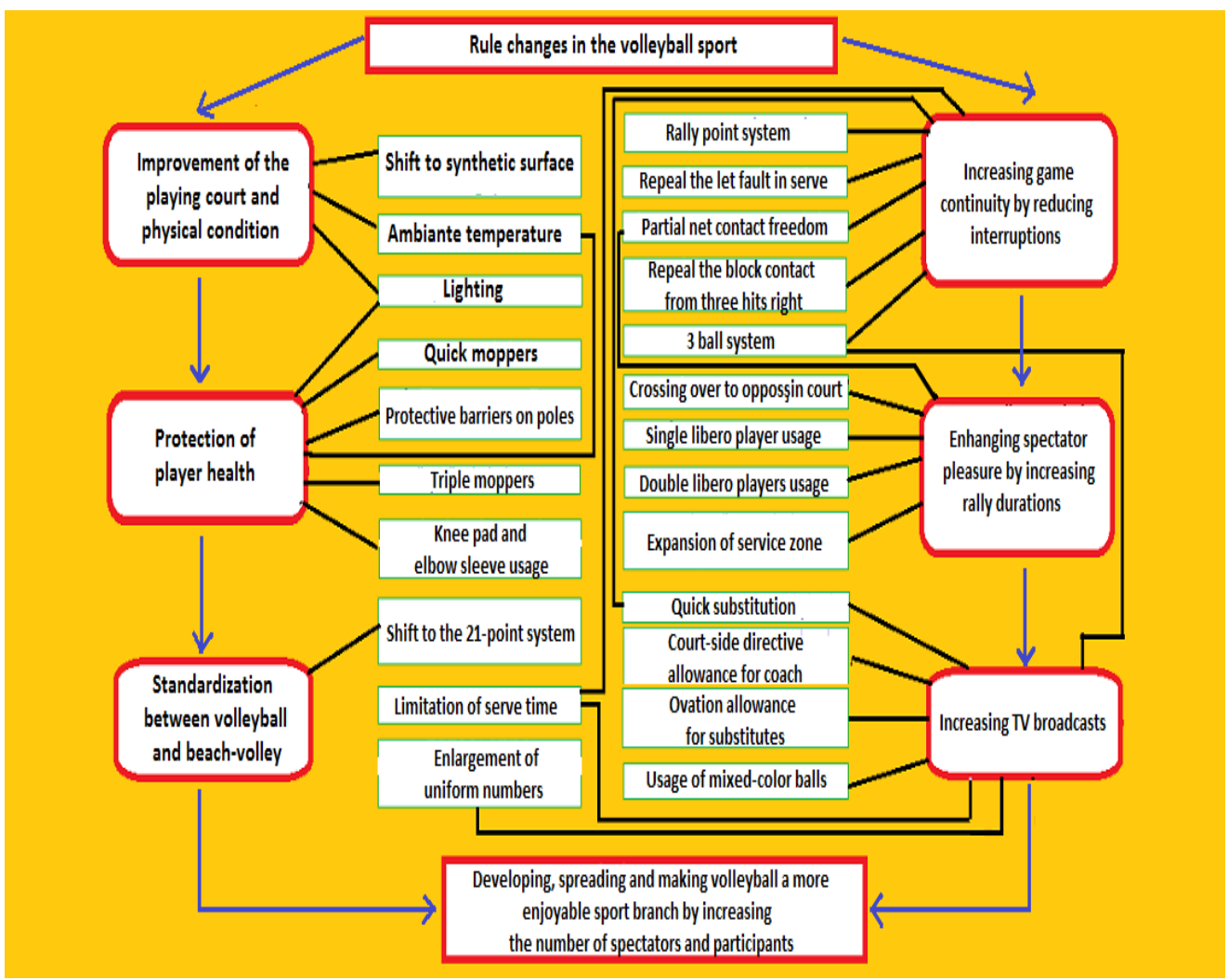

Figure 2. Conclusion model related to the changes made in the Volleyball Game Rules

It has been noted upon examining the findings attained as a result of the analysis that the major rule changes made are grouped under six main headings. These may be listed as, "improvement of the playing court and physical conditions", "protection of player health", "increasing game continuity by reducing interruptions", "enhancing spectator pleasure by increasing rally durations", "increasing TV broadcasts" and "standardization between volleyball and beach volleyball". 


\section{Conclusions}

Tens of rule changes have been analyzed in from different rule books during the coding and thematizing processes. It has been noted that many of the major rule changes serve more than one purpose. Changes such as "having the game played on a synthetic surface", "standardization of the ambient temperature", "standardization of the lighting etc.", are considered changes made with the purpose of "improving the playing court and physical conditions". Changes such as the "assignment of quick moppers" and "assignment of triple moppers" have been put into practice by drying up the court surfaces that get wet due to various reasons. In order to prevent the players from skidding and injuring themselves, it is thought that changes such as "installation of protective barriers on net posts "and"usage of knee pads, arm rests and protective materials", however, are changes that have been made with the aim "to protect player health" by preventing severe collision of players against the posts or the surface.

Rule changes such as the "shift to the rally point system", "let fault repeal in services", "block no longer counted as the first team's three hits", "three ball system", "partial net contact freedom", "limitation of service execution time to eight seconds" and "quick substitution" however, are thought to serve the purpose of "increasing game continuity by reducing interruptions" in terms of preventing the interruption of the game where this would cause the spectators and players to cool off and lose their interest in the game.

"Partial net contact freedom" has been put into practice in order to allow continuity of the rally in net contacts without affecting the game and the opponent. Changes such as "single and two libero player usage" and "crossing over to the opponent's court" are thought to provide an advantage in terms of enabling extension of rally durations by enhancing the defensive skills of the teams. The expansion the service zone however, provides opportunities to employ different play strategies. It is considered that this is one of the changes made to "enhance the spectator pleasure by increasing rally durations". The "shift to rally point system" may be considered a significant rule change as it provides more predictable broadcast durations for broadcasting organizations by reducing the competition durations that would take about three to four hours to approximately 90 to 100 minutes. "Quick substitution” provides advantages in terms of preventing the extension of the total game duration due to substitutions. The changes such as the "court-side directive allowance for coaches" and "allowing the substitute players' ovations, within the limits of sportsmanship, to support their teams" however, enhance the teams' power of struggle. It may be thought that these changes increase the performance of the players in the game and thereby, create a visual richness and increase the number of spectators. Considering the situation with this point of view, it may be thought that these rule changes serve the goal of increasing TV broadcasts. In addition, all other changes made with the aim of "increasing continuity by reducing interruptions during the game" and "enhancing spectator pleasure and enjoyment by 
extending the rally duration" as well, by making volleyball into a sport which is enjoyable to watch, also serve the goal of increasing TV broadcasts. It has been reported that the rule change regarding the "shift to the 21 point system" from the 25 (set) point system applied at the present is, being made with the aim to "make a standardization between beach volleyball and volleyball" by means of applying similar rules in both types of volleyball. With the rule changes made, the volleyball sport is becoming a sport branch which is becoming more enjoyable to watch, where the number of its spectators and participants are gradually increasing. At the same time, significant increases have been experienced in TV broadcast as well, and it is observed that changes made in this regard have attained their targets to a large extent. In spite of these positive developments however, there are players, trainers, referees, spectators and sports commentators who still believe that certain changes may lead to an increase in the number of player injuries although these may increase continuity of the game. As it would not be desired for any rule change to produce results that would endanger player health, even unintentionally, it is thought that it is necessary to consider the "partial freedom of net contact" as the subject of future research.

\section{References}

1. FIVB Official Web Site. (2014). "Volleyball History” web page. Accessed URL: http://www.fivb.org/en/volleyball/History.asp, France, Accessed date: 04. 01.2016;

2. FIVB Official Web Site. (2014). “220 Affiliated National Federations” web page, Accessed URL: http://www.fivb.org/en/fivb/ListFederations.asp, France, Accessed date: 04. 01.2016;

3. Volleyball.com Web Site. (2015). "Volleyball History” web page, Australia Accessed URL: http:/www.volleyball.com/volleyball-101/history-of-volleyball, Accessed date: 05. 01.2016;

4. FIVB Official Web Site. (2016a). “Official Volleyball Rules” web page, France, Accessed URL: http://www.fivb.org/EN/Refereeing-Rules/). Accessed date: 05. 01.2016;

5. FIVB Official Web Site. (2012). “33rd FIVB World Congress” web page, France, Accessed URL: http://www.fivb.org/EN/Congress/2012, Accessed date: 06. 01.2016;

6. FIVB Official Web Site. (2010). “32nd FIVB World Congress” web page, France, Accessed URL: http://www.fivb.org/EN/Congress/2010, Accessed date: 06. 01.2016;

7. FIVB Official Web Site. (2008). “31st FIVB World Congress” web page, France, Accessed URL: http://www.fivb.org/EN/Congress/2008, Accessed date: 06. 01.2016;

8. FIVB Official Web Site. (2016b). “Technical Supervisors and Referee Delegates complete seminar in Lausanne", France, Accessed URL: http://www.fivb.org/en/FIVB/viewPressRelease.asp?No=58784\& Language=en, Accessed date: 09. 01.2016. 